\title{
Close the Metacognitive Equity Gap: Teach All Students How to Learn
}

\author{
Saundra Y. McGuire
}

https://doi.org/10.36896/4.1ep1

\section{ABOUT THE AUTHORS}

Dr. Saundra Y. McGuire is director emerita of the Center for Academic Success and professor emerita of chemistry at Louisiana State University. She is an internationally recognized educational consultant and the author of Teach Students How to Learn (2015) and Teach Yourself How to Learn (2018). She is also an American Chemical Society and Council for Learning Assistance and Developmental Education Associations Fellow.

\section{Disclosure Statement}

No potential conflict of interest was reported by the author.

\section{Author Note}

I would like to acknowledge Stephanie McGuire for her exceptional assistance with this article.

$\mathrm{n}$ his seminal book, Toward Excellence with Equity: An Emerging Vision for Closing the Achievement Gap, Ferguson (2008) persuasively argued that the achievement gap between students from different racial groups is not the result of a difference in ability, attitudes or work ethic between groups, but rather a difference in the academic skills acquired. Often, we in the academic community use the term educational equity when referring to closing the achievement gap between different groups of students, such as majority versus minoritized, lower socioeconomic versus higher socioeconomic, or students from well-resourced versus under-resourced schools. (Harris \& Herrington, 2006). I have recently begun using a parallel term, metacognitive equity, to describe closing the gap between students who use metacognition (effective thinking and learning strategies) and those who do not. I posit that it is the gap in metacognitive strategies that contributes most to the persistent achievement gap and that all students must be taught how to learn.

Metacognition is a term coined by Flavell (1976) to indicate thinking about one's own thinking. Although this is an overly simplified definition of metacognition, it is one I use with students because they can more easily grasp the meaning of the term than if I use a more involved definition. When I explain metacognition to students, I tell them,

It's like you have a big brain outside of your brain, analyzing what your brain is doing. It's asking your brain questions to see if you really understand something or if you've just memorized it last night because the test is today. It's making sure you're using strategies to really understand what you're reading, rather than just looking at the words as you hear them in your head.

Metacognition involves planning, monitoring, controlling, and making adjustments to the way one attempts to learn something. Because there is overlap between cognitive and metacognitive strategies, and also between study skills and cognitive strategies based on the specific situation, I intentionally blur the distinctions in my book, Teach Students How to Learn (2015). This prevents students and faculty from getting mired in details that would lessen the impact of delivering the strategies. For purposes of this discussion, however, I distinguish the terms in the following way. Cognitive strategies are used to acquire and retain information. They include memorizing, problem solving, making mind maps, using mnemonics, etc. Metacognitive strategies involve determining which cognitive strategies should be used in a particular situation. The metacognitive strategies such as reflection, self-questioning, and analyzing one's strengths and weaknesses, allow an individual to more effectively use cognitive strategies. Study skills, on the other hand, involve activities such as note-taking, time management, and test preparation. Study skills can be combined to form cognitive strategies, and metacognitive strategies allow one to evaluate the effectiveness of different cognitive strategies and adjust them to increase success with learning tasks. In my view, the gap in cognitive and metacognitive strategies plays the biggest role in the achievement gap. For simplicity's sake, however, and also to emphasize the decisive role of metacognition, I refer to the metacognitive equity gap.

Although I am quite confident in teaching students these strategies today, I was not always. Before becoming the director of the Center for Academic Success at Louisiana State University, I was oblivious to the possibility that students could be transformed from academic failures to academic superstars within a matter of weeks.

\section{Corresponding Author}

Dr. Saundra Y. McGuire

Email: smcgui1@lsu.edu 
What precipitated my transformation from skeptic to enthusiast? At LSU, a talented learning professional taught me how to present effective learning strategies, and I began to marvel at their impact not only on the students but also on my own thinking and learning. Over the last 20 years, I have seen countless students transform their academic performance by using simple metacognitive learning strategies that show them how to learn. If metacognitive strategies could be delivered to all students at our institutions starting in the first year-if all students could be taught how to learnthen our institutions could achieve metacognitive equity. As educators, why are we not there already? I suggest several contributors to the metacognitive equity gap: (a) the commonly held notion that a student's intelligence is essentially fixed by the time they enter school, (b) the lack of opportunity for highlevel learning in K-12 schools, and (c) the invisibility of the metacognitive gap to students from under-resourced K-12 schools.

The first contributing factor is that not enough people know that it is possible to teach students how to learn. The idea of intelligence as fixed is still too widespread. In fact, one of the two students mentioned earlier recounted a meeting during her sophomore year with a professor with whom she wanted to do undergraduate research. The professor asked her why she even thought she would be able to major in neuroscience because she had a $C$ average in the neuroscience course she was taking that semester. She told me that she went to her room and spent the rest of the afternoon crying, trying to decide what else she might pursue as a major. However, when she learned that she could improve her performance by implementing more effective strategies, she used them to raise her grades, earning all A's during her senior year.

Many people have a fixed mindset because they have personal experience comparing themselves to other students while they were in school and may have labeled themselves as "good at reading but bad at math," for example. To close the metacognitive equity gap, faculty and academic staff must constantly and emphatically communicate the fact that simple metacognitive learning strategies can be transformative. To make the deepest structural changes at any educational institution, metacognitive learning strategies should be introduced to all students as early as possible and continually reinforced as they move through the institution.

A second cause of the metacognitive equity gap is the lack of higher-level learning throughout $\mathrm{K}-12$ education. This begins with the stratification of elementary or middle school students into different learning levels without first teaching them metacognitive strategies. Over time, this stratification widens the metacognitive equity gap because, too often, only students at higher learning levels are required to demonstrate higher-order thinking skills. To make matters worse, students who attend under-resourced schools may not even have access to courses like Advanced Placement or International Baccalaureate classes. Indeed, the U.S. Department of Education's (2012) Office of Civil Rights collected data indicating that students from under resourced schools are more likely to be less academically challenged.

I saw firsthand how sorting students into different learning levels can influence academic development when our younger daughter entered high school after our family relocated. As a 9th grader, she was placed in a mid-level math class but was moved to the honors class within a few weeks. The two classes had the same name and used the same textbook, so I was quite surprised to discover that they were as different as day and night. Homework for the midlevel class consisted exclusively of problems very similar to the worked examples presented in the chapter, whereas the honors students were expected to solve the most difficult problems offered by the textbook. The development of our daughter's thinking skills would have taken a very different journey if she had remained in the mid-level class.

One additional contributor to metacognitive inequity is that students from under-resourced schools are largely unaware of the more advanced thinking and learning skills that students in other schools have been taught and regularly employ. When these students get much better grades than most of their peers, it is logical for them to mistakenly believe that they are prepared to compete at the highest levels at elite institutions. Moreover, as Putnam (2015) argued, students from economically disadvantaged backgrounds have less access to mentors (Sebenius, 2016). In addition to the insider knowledge and needed influence that mentorship provides, I argue that two of the 
biggest contributions mentors make to students are that they model metacognitive thinking skills and encourage students to persist through challenges. Minoritized students and those from disadvantaged backgrounds often miss out on this avenue for absorbing metacognitive thinking habits and receiving encouragement to keep going after setbacks. Tutors, peer mentors, and coaches can model these skills while encouraging students to persist, even in the face of initial failure.

Fortunately, educators already have the tools to address the problem of metacognitive inequity. Metacognitive skills can be taught at any and every stage of a student's education. Considering the "whys, hows, and what ifs" instead of merely memorizing the "whats" can easily be deliberately modeled for elementary school children. In my 30year speaking career, I have heard from many K-12 teachers and students successfully teaching and using metacognition in elementary, middle school, and high school classrooms. Even if students sit down in their first college class without sufficient learning strategies, educators can still equip them to excel. During my own 50-year teaching career, I have facilitated countless sessions with undergraduate, graduate, and professional school students whose academic performance was improved by using metacognitive learning strategies.

Often, whether or not a student possesses effective learning strategies - rather than any lack of innate ability or talent-makes the difference between academic success and discouraging failure. The heartening news is that metacognitive learning strategies can be taught, sometimes with immediate and substantial improvements in academic performance (Cook et al., 2013; McGuire, 2015, 2018). For example, in June 2021, two students from a highly selective university who used metacognitive strategies to improve their grades shared their thoughts about that process with me. One student, a recent neuroscience graduate, talked about the dismay she felt when she realized that her public school experience had not equipped her with the strategies for success that students from more elite schools used to their advantage. She told me that groups of students from public schools would regularly socialize and express their belief that they would never be able to earn the A's that the more prepared students were achieving. However, when she learned about metacognition, Bloom's taxonomy, and the importance of developing a growth mindset, she said that she saw her grades and her confidence steadily improve, culminating in a 4.0 GPA during her senior year. The second student, a public policy pre-med major, recounted how learning about metacognition enabled him to develop a deeper understanding of concepts, apply information to new situations, and implement more sophisticated learning strategies for different types of courses. Both students told me that they had learned these strategies through a combination of talking with the director of the campus learning center, attending faculty-led sessions where students discussed learning strategies, and reading Teach Yourself How to Learn, a book I also authored in 2018.

In the example above, the university's academic support program provided the resources for these students to achieve metacognitive equity with their better prepared peers. Academic support programs are uniquely prepared to foster metacognitive equity. The academic coaches, tutors, Supplemental Instruction leaders, and academic peer mentors learn these strategies in their training and can teach them to students. Additionally, academic support staff are sometimes the primary sources for inspiring hope and confidence in students who have lost optimism after performing lower than they expected on course assessments. The myriad success stories that our centers have collected stand as proof that failure has nothing to do with how smart a student is but rather the strategies they use in their learning.

There is a growing body of literature investigating the impact of teaching metacognitive strategies, sometimes in conjunction with other pedagogical practices. Examples include Cook et al. (2013), Kaldor and Swanson (2018, 2019), Swanson et al. (2021), Muteti et al. (2021), Mutambuki et al. (2020), and Benko et al. (2019). A university student who used metacognition to improve academic performance recently published an account of her experience (Chen, 2020). Certainly, the role of metacognition in learning has been of interest since at least the 1970s when Flavell (1976) coined the term. There are plenty of additional examples in the literature, such as Rickey and Stacey (2000), which presciently argue for the widespread application of metacognition.

Teaching people metacognitive learning strategies is possible at any age. I look forward to a future in which the metacognitive equity gap has been closed, and every student is routinely exposed to thinking and learning strategies that inspire a deep love of independent learning. I envision a time when the idea that some students are smart, and some are not, has been completely replaced by the idea that some students have metacognitive learning strategies while others do not; and all facultypreschool through graduate and professional school-will actively teach the necessary skills so that all students are operating on a level playing field. 


\section{References}

Benko, M. H., Vogelsang, K.M., Johnson, K.C., \& Babij, A. R. (2019). Strategies to prevent cognitive overload: A team-based approach to improving student success and persistence in a gateway introductory chemistry course. In S. Kradtap Hartwell \& T. Gupta (Eds.), American Chemical Society Symposium Vol. 1330, Enhancing retention in introductory chemistry courses: Teaching practices and assessments (pp. 187-200). ACS Publications. https://doi.org/10.1021/ bk-2019-1330.ch012

Chen. S. (2020). Book review: Teach yourself how to learn. Journal of Food Science Education 19, 120-121. https://doi.org/10.1111/15414329.12203

Cook, E., Kennedy, E., \& McGuire, S. Y. (2013). Effect of teaching metacognitive learning strategies on performance in General Chemistry courses. Journal of Chemical Education, 90, 961-967. https://doi.org/10.1021/ed300686h

Ferguson, R. F. (2008). Toward excellence with equity: an emerging vision for closing the achievement gap. Harvard Education Press.

Flavell, J. H. (1976). Metacognitive aspects of problem solving. In L. B. Resnick (Ed.), The nature of intelligence (pp. 231-236). Lawrence Erlbaum.

Harris, D. N., \& Herrington, C. D. (2006). Accountability, standards, and the growing achievement gap: Lessons from the past half-century. American Journal of Education, 112(2), 209-238. https://doi.org/10.1086/498995

Kaldor, E., \& Swanson, H. J. (2018, November 15). A campus-wide strategy to develop metacognition in gateway science courses [Conference session]. Professional and Organizational Development Network in Higher Education. Portland, Oregon, United States.

Kaldor, E. \& Swanson, H. (2019). How can you elevate metacognition on your campus? Try the ace-your-course challenge. Forum for Teaching \& Learning, 28(2), 5-7. https://doi.org/10.1002/ntlf.30186

McGuire, S. Y. (2015). Teach students how to learn: Strategies you can incorporate into any course to improve student metacognition, study skills, and motivation. Stylus Publishing.

McGuire, S. Y. (2018). Teach yourself how to learn: Strategies you can use to ace any course at any level. Stylus Publishing.
Muteti, C. Z., Zarraga, C., Jacob, B. I., Mwarumba, T. M., Nkhata D.B., Mwavita M., Mohanty, S., \& Mutambuki, J. M. (2021). I realized what I was doing was not working: The influence of explicit teaching of metacognition on students' study strategies in a general chemistry I course. Chemistry Education Research and Practice, 22, 122-135. https://doi.org/10.1039/D0RP00217H

Mutambuki J. M., Mwavita, M., Muteti, C. Z., Jacob, B. I., \& Mohanty, S. (2020). Metacognition and active learning combination reveals better performance on cognitively demanding general chemistry concepts than active learning alone. Journal of Chemical Education 97(7), 1832-1840. https://doi. org/10.1021/acs.jchemed.0c00254

Putnam, R. D. (2015). Our kids: The American dream in crisis. Simon \& Schuster.

Rickey, D. \& Stacy, A. M. (2000). The role of metacognition in learning chemistry. Journal of Chemical Education 77(7), 915-920. https://doi.org/10.1021/ed077p915

Sebenius, A. (2016, January 13). The importance of high-school mentors. The Atlantic. https://www.theatlantic.com/education/ archive/2016/01/mentorship-in-publicschools/423945/

U.S. Department of Education. (2012, March 6). New data from U.S. Department of Education highlights educational inequities around teacher experience, discipline and high school rigor [Press release]. https://www.ed.gov/news/press-releases/ new-data-us-department-educationhighlights-educational-inequities-aroundteacher-experience-discipline-and-highschool-rigor 